\title{
Development of Game for Self-Help Toilet Learning for Children with Autism
}

\author{
Rahadian Kurniawan ${ }^{1}$, Wuriandietry Mayang Purnamasari ${ }^{2}$, Restu Rakhmawati ${ }^{3}$, and \\ Dimas Panji Eka Jalaputra ${ }^{4}$ \\ ${ }^{1,2}$ Department of Informatics, Faculty of Industrial Technology, \\ Universitas Islam Indonesia, Yogyakarta 55501, Indonesia \\ ${ }^{3,4}$ Magister of Informatics, Faculty of Industrial Technology, \\ Universitas Islam Indonesia, Yogyakarta 55501, Indonesia \\ Email: ${ }^{1}$ rahadiankurniawan@uii.ac.id, ${ }^{2}$ wuriandietrymayang@gmail.com, \\ ${ }^{3}$ resturakhma@gmail.com, ${ }^{4}$ die.ejp@gmail.com
}

\begin{abstract}
This study aims to develop a video game for toilet training materials as a medium for self-help learning for children with autism. Toileting skill is one of the basic self-help skills that children should master. In fact, teaching new things to children with autism is challenging. It requires a proper method to deliver the materials to these children. One of the effective learning media to teach self-help is to use visual media like video games. By using video games, children are expected to play and learn self-help skills, particularly about toileting. In addition, the video game is developed by applying certain design principles that fit with the needs of children with autism. The software is tested for its functionalities. Moreover, an implementation test is done by using observation communication analysis. Based on the results, the researchers conclude that the developed video game has implemented the proper design and materials related to toileting in accordance with the needs of children with autism. The respondents show positive results for using the video game.
\end{abstract}

Index Terms-Toilet Training, Self-Help, Children with Autism, Video Games

\section{INTRODUCTION}

$\mathbf{P}$ ERSONAL hygiene is important to maintain health and for the process of social interaction. Personal hygiene is inseparable from the process of toileting. Toileting is an ability to recognize the urge to defecate and any activities related to it such as taking a bath, brushing teeth, urinating, and defecating [1]. The process of teaching toileting skill is called toilet training. Toilet training is taught early to increase personal independence. Moreover, toileting skill is the main skill in building self-help that is important for independence. However, this can be a significant problem for individuals with or without developmental

Received: Oct. 30, 2017; received in revised form: Dec. 21, 2017; accepted: Jan. 16, 2018; available online: Apr. 25, 2018. disorder [2]. In general, normal children may know when to urinate or have bowel movements properly at the age of 3-5 years [3, 4]. However, a few studies have shown that children with autism experience greater difficulty in mastering toileting skill properly.

Toileting skill is one of the basic self-help skills that children with autism should master. The combination of social skills and self-help skills can improve children's independence and success in the community [5]. According to Ref. [6], the individuals with lower adaptability experience higher difficulties in toileting. Research conducted by Ref. [7] to 102 children with autism showed that $66 \%$ of them at the age of 3.5 years still wet themselves and $71 \%$ do not defecate in proper places. This certainly becomes a serious problem since those findings result in negative impacts on personal hygiene, self-confidence, physical comfort [8], independence, social acceptance [9], and burden to caregivers.

Toileting skills may include the ability to recognize the needs of urinating, holding in urine, sitting on the toilet, using toilet paper, flushing, getting undressed, getting dressed, and washing hands [10], not urinating in improper places, and taking a shower. In addition to experiencing cognitive problems in recognizing the needs of toileting, Ref. [11] mentioned that $30 \%$ of children with autism had fear of toileting process, and it took at least three years for them to master toileting skills.

Teaching new things for children with autism is challenging. It requires a proper method to deliver the materials to the children. One method that can be used is to use visual-based interventions. Children with autism can understand more easily by using visual $[12,13]$. The objective of this study is to develop a game that can help children with autism to learn 
Cite this article as: R. Kurniawan, W. M. Purnamasari, R. Rakhmawati, and D. P. E. Jalaputra, "Development of Game for Self-Help Toilet Learning for Children with Autism", CommIT (Communication \& Information Technology) Journal 12(1), 1-12, 2018.

about personal hygiene skills in a fun way and to assess the success level of the developed game in teaching toileting skills. In this study, the game is selected as a learning medium because it is not only fun, but it also contains video animation. It can minimize the needs for focus and language because they only need to watch and listen to the important information [14]. By combining visual and contents that are appropriate for children with autism, this game is expected to be an alternative in teaching toileting skills. The main contribution of this study is a strategy of intervention design using a video game. It can also be adopted by other researchers to develop video games for children with autism.

\section{RELATED RESEARCH}

A few studies had reported success in toilet training for children with autism. References [8, 15] reported that there were positive results in the implementation of operant conditioning technique [16], but they did not report about the cognitive or language skills of the participants. Based on the results of the study by Ref. [2], the majority of toilet training programs adopted the model developed by Ref. [17]. Operant conditioning method was a method of rewarding the participants if they succeeded in carrying out an order, and punishing them if they failed to obey the order. Although training would increase toileting skills, the use of punishment method was considered inappropriate for ethical reasons.

In the field of information technology, the studies regarding educational media for teaching toileting skills are rare. The study on the use of video modeling technology as alternative educational media to teach toileting skills for children with autism was carried out by Ref. [1]. It was by using video to teach children to go to the toilet every few hours routinely. After six weeks of the study, the results started to be evident among the respondents. Children who watched the video tended to more regularly go to the toilet and defecated in accordance with the scheduled time compared to children who did not watch the animated video.

The studies using video modeling to teach toilet training were conducted by Refs. [18, 19]. These studies built a video modeling technology to teach the ability to walk to the toilet if children with autism felt the urge to urinate. Although it reported a positive attitude of children with autism, the testing was done only when the respondents watched the video. There was no further investigation related to the situation when the children did not watch the video in the long term. Based on these studies, there were some disadvantages of the use of video modeling. The children got bored when the videos were repeatedly played [1]. Moreover, the video was not animated and only used models. Toilet training video that used models did not show genital parts [18]. This made them unable to understand the scene of urinating and cleaning after urination. In relation to this, it was suggested to use animated video [20].

Toilet training is a new lesson that must be understood by children. As a new thing, teachers at school and parents at home should teach the same routine. Hence, children can understand quicker and get used to it. However, it is difficult to be practiced at home. Often, parents cannot continue toilet training as their child shows signs of discomfort and unpreparedness of this new habits [21]. The discomfort arises because of the unsuitable teaching methods for the children's condition. It makes some difficulties for the teacher to give the training to children with autism. According to teachers and experts, children with autism are easier to adapt new habits with audiovisual media. One of the media that children love is video game. There is currently no research in using video games as a method to teach toilet training for children with autism. The methods that have been used are alarm enuresis, video modeling, scheduled seats, diaper or pad removal, and communication or visual training [6].

There are many things to consider when teaching toileting for children with autism. Toileting is closely related to the preference of children's needs especially the differences in the toileting process of boys and girls. For example, boys and girls have different processes of urinating. Therefore, it is necessary to have special arrangements in developing toileting learning media for children with autism. This study focuses on the necessary needs to develop toileting learning media for children with autism. By using video games, the special arrangements can be applied.

\section{RESEARCH METHOD}

Analysis-Design-Development-ImplementationEvaluation (ADDIE) method is used to guide the development of the game and other infrastructure, to support an effective and dynamic learning activities, and to provide support for learning performance [22]. Based on the method, there are several steps.

\section{A. Analyze}

The analysis phase is the first phase in developing the game. The analysis is carried out by observing a special need school (Sekolah Luar Biasa, SLB) for autism. This phase aims to obtain the following needs:

1) Determining learning goals. Determining the learning goals is done by discussing with teachers, 
Cite this article as: R. Kurniawan, W. M. Purnamasari, R. Rakhmawati, and D. P. E. Jalaputra, "Development of Game for Self-Help Toilet Learning for Children with Autism”, CommIT (Communication \& Information Technology) Journal 12(1), 1-12, 2018.

psychologists, and specialists of children with special needs. Then, the discussions result in the learning goals of this game. The goal is to build a video game as alternative medium of toilet training for children with autism.

2) Analyzing the existing learning method. Based on the analysis, the existing learning method uses video modeling [1, 18, 20]. It is adapted from the model developed by Ref. [17].

3) Analyzing similar learning games. The process of analyzing similar learning games is done by searching online journals and in the apps store. The results show that toileting-related learning games for children with autism are still very limited. There is no game related to toilet training learning that is particularly designed for children with autism.

4) Analyzing ideal ways of learning. To find out about the ideal ways of learning, the researchers conduct observation in two SLB for autism for two weeks. In addition, the researchers also conduct interviews with SLB teachers, specialists, as well as psychologists to determine the ideal learning technique for toileting.

\section{B. Design}

The process of designing the game is influenced by the analysis process conducted through interviews, observation, and literature studies on children with autism, teachers, psychologists, and specialists.

1) Intervention design using video game. In the process of designing the proposed game, the researchers develop an intervention design strategy using video games as shown in Fig. 1.

a) Component Design. The design of these game components adopts the study by Ref. [23], which summarized some studies by Refs. [2428]. Those are several examples of the game design development framework for health-related application. As a note, the component design of this game has been consulted with two psychologists of children with autism and a special education specialist. The following is the component designs used in the development of this game:

Storyline. The storyline is an important design component and is used in several previous game design theories (Social Cognitive theory [24], Transportation theory [28], and Elaboration Likehood Model [26]). There are four stories in this game. The first story tells about a child who is playing inside the house. Then, she/he has a stomachache. She/he has to go to the toilet to defecate. The players have to help the child to go to the toilet. After going to the toilet, the players help the child to do the steps of defecating in the toilet such as taking off her/his pants, flushing the toilet, washing her/his hands, and putting on her/his pants. The second story tells about a child who wants to take a shower after playing. The players have to help her/him to find the bathroom so she/he can take a bath. Inside the bathroom, the players help her/him to do the steps of taking a bath. The steps include taking off her/his clothes and pants, applying soap, rinsing the body, wiping the body with a towel, and putting on clean clothes and pants. The third story tells about a child who is playing in her/his house yard. While playing, she/he feels the urge to urinate. The players must help her/him to hold in urine so that she/he does not urinate in an improper place. The fourth story is about washing hands. A child wants to eat, but her/his hands are dirty. The players must help her/him to go to the sink and wash her/his hands until it is clean. After eating, the players must also help her/him to wash her/his hands from the remaining food.

Mini Game. Mini-game is a game design component that is also used in several previous game design theories (Social Cognitive theory [24] and Self-Determination theory [25]). The mini-game is shown on the time that the child is waiting while he is defecating. She/he must break bubbles in the bathroom during the bowel movement. This mini-game aims to introduce the players that they can do something fun when she/he has not finished defecating.

Feedback. Feedback is a game design component used in several previous game design theories (Social Cognitive Theory [24], SelfDetermination theory [25], and Elaboration Likehood Model [26]). Feedback in this game is designed to show the interaction between the game and player. It is in the form of compliments to motivate the player and give him stars when she/he completes a challenge. On the other hand, when the players choose the wrong choice, then feedback will show up helping about options to select.

Choice. The choice is a game design component that can be used in games as a learning goal. The choice is found in previous design theory (Self-Determination theory [25]). This game provides various options for the player. On the main page, there are two choices, bath- 
Cite this article as: R. Kurniawan, W. M. Purnamasari, R. Rakhmawati, and D. P. E. Jalaputra, "Development of Game for Self-Help Toilet Learning for Children with Autism", CommIT (Communication \& Information Technology) Journal 12(1), 1-12, 2018.

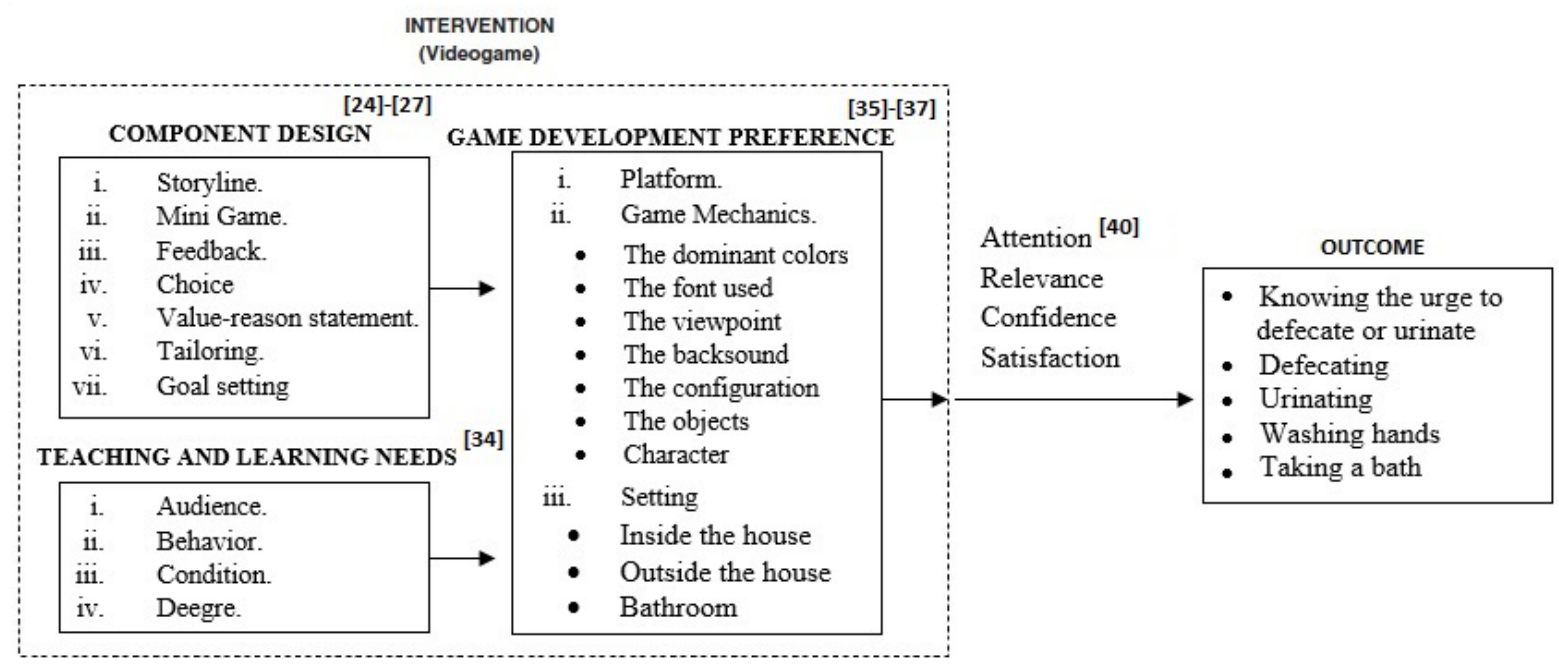

Fig. 1. Intervention diagram.

room, and bedroom. The choices are provided to make the players identify bathroom from the other rooms. The players can identify bathroom based on the things found in the bathroom such as bathtub and closet. In addition, the players can identify bathroom for boy and girl by seeing the symbol found next to the bathroom. On the display of bathroom page, there are two choices, bathtub or water closet. The players should determine the choice according to the needs in the story. If the character wants to defecate, the players should choose the water closet. Meanwhile, if the character wants to take a bath, the players should select the bathtub. The available options are designed in limited number to reduce the level of difficulty for the users [29]. In this game, there are only two or three options. The number of options in the game is determined based on the interview process with the specialist and teachers at SLB.

Value-reason statement. Value-reason statement is an important design component in the development of learning games. This component is usually linked to feedback on the players choices in the form of words. This component is also used in the previous game development theory (Self-Determination theory [25]). This game is designed so that the players can get lessons or scores when playing this game. These scores are given through feedback and commands in the game. For example, the players will receive scores if they can maintain hygiene after urination/bowel movement like choosing to wash hands after defecation/urination.

Tailoring. Tailoring is a mandatory component design in a game intended for children with autism. This regards the fact that children with autism have diverse characteristics that are difficult to generalize. Tailoring is also used in the previous game development theory, that is Elaboration Likehood Model [26]. This game is designed to adjust the needs of its users. This game provides the choices of gender and types of toilet. Providing the choices of gender aims to enable the players to choose the character according to their gender and daily environment. Based on Ref. [30], male children with autism prefer to select a male character, while female children with autism are more likely to select a female character. Thus, it is necessary to provide options that can be adjusted to the childrens condition. This character selection is important because there are differences in the toileting process between male and female. By selecting an appropriate character, the players can learn about appropriate toileting skills. In addition, the proposed game allows various configurations according to the needs of each player. The configurations are related to enable texts or sound. For children who cannot read, all commands and feedback are given through audio, Meanwhile, for those who do not like the sound, the command and feedback are given through texts. According to Ref. [31], the configuration is the best way to improve the accessibility of computer-based interventions for 
Cite this article as: R. Kurniawan, W. M. Purnamasari, R. Rakhmawati, and D. P. E. Jalaputra, "Development of Game for Self-Help Toilet Learning for Children with Autism”, CommIT (Communication \& Information Technology) Journal 12(1), 1-12, 2018.

various users. In addition, Ref. [32] concluded that individual customization for children with autism was necessary to enable the preferred way of receiving feedback effectively.

Goal setting. Goal setting is a component of game design that is needed to teach specific skills to the players. This component is used in some previous games development theory (Social Cognitive theory [24] and SelfDetermination theory [25]). This game provides choices of the menu to teach toileting such as urinating/defecating, taking a bath, washing hands, and holding in urine or feces. The settings in this game allow teachers to determine the materials that they will use according to the needs of children. Teachers can teach one material continuously to emphasize the lesson to children.

b) Teaching and learning needs. From the analysis of the interviews and observations of teachers, psychologists and specialists, and the results of the literature review, the researchers have mapped the teaching and learning needs using ABCD model [33]. It includes:

Audience. The targeted audiences of this game are children with autism who are 7-12 years; children that understand basic commands; and children that can use mobile devices (tablet/smartphone).

Behavior. Behavior includes several targets from the use of this game, such as recognizing the urge of urinating or defecating and knowing the location of toilet, how to clean the body and feces or urine after defecating or urinating, how to take off pants before defecating and put on pants after finishing, how to take a bath, and how to wash hands.

Condition. The appropriate conditions to use this game are as follows. The children are accompanied by someone who can control them. The game is not played for more than 45 minutes. Then, the game is only played during break time.

Degree. The degree is a quantitative measure to see the achievement of the proposed game. There are several measures to assess in the development of this game. Children are willing to play this game for more than 10 minutes. Children do not lose interaction with teacher/ supervisor when playing. Children can execute the targets of behaviors with the intervention of the game for a week. c) Game development preference. The process of component design and pre-designed teaching and learning needs affect game development preference. For this preference, in addition to adjusting to component design and teaching and learning needs, the researchers adapt the game development preferences from Refs. [34-36]. Some of them are:

Platform. The platform used in this game is Android tablet device. Previous research has found that $60 \%$ of 5 doctors and 11 therapists agree that touch screen devices are more preferable for children with autism [37]. Furthermore, handheld devices are more engaging for children in various age to be involved in learning activities. Based on an interview with an expert, Android platform is suitable for children with autism under 18 years old.

Game Mechanics. There are several game mechanics in this game. The dominant colors of this game are blue and red [35]. The font used in this game is Verdana [38]. The viewpoint in this game uses overhead view [35]. The backsound in this game uses music for children. The configuration in this game includes enabling and disabling sound and texts, the configuration of the character gender, and configuration of the type of toilet. The objects contained in this game are any objects that are appropriate in childrens daily lives. This game includes boy and girl character that can be selected according to the needs of children [35].

The setting of location. There are three locations in this game. Those are inside the house; outside the house; and bathroom.

d) Outcome. The proposed video game-based intervention is expected to meet output targets by motivating children through the model Attention, Relevance, Confidence, and Satisfaction model (ARCS) proposed by Ref. [39]. The preference process of game development will affect the outcome shown by children with autism. It is expected that after playing this game, they will have the independent ability regarding knowing the urge to defecate or urinate, defecating, urinating, washing hands, and taking a bath.

2) Menu in the game. Based on the results of designing the learning materials, there are menus that include all these materials. These menus are described in the VTOC diagram in Fig. 2. Visual Table of Content (VTOC) diagram shows the menu contained in the game. The explanation of 
Cite this article as: R. Kurniawan, W. M. Purnamasari, R. Rakhmawati, and D. P. E. Jalaputra, "Development of Game for Self-Help Toilet Learning for Children with Autism", CommIT (Communication \& Information Technology) Journal 12(1), 1-12, 2018.

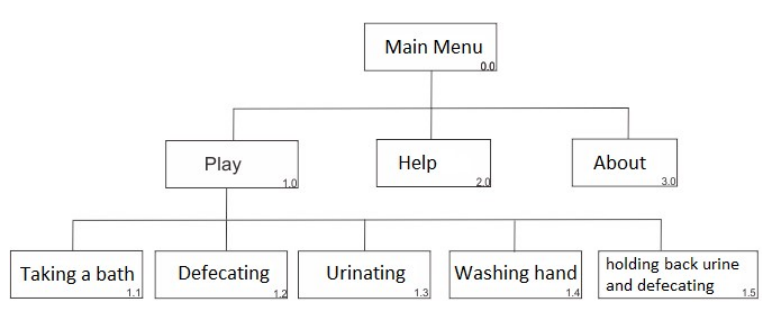

Fig. 2. VTOC diagram.

VTOC diagram is as follows:

a) Scenario 0.0. The main menu consists of three menus. There are Play to start the game, Help to get instruction of the game, and About to get information about the game.

b) Scenario 1.0. Play menu will start the game that consists of five toileting skills such as taking a bath, bowel movement, urinating, washing hands, and holding in urine and feces. The players are allowed to choose boy or girl character, according to his or her gender. The character selection is specific customization in this game to adjust to the player. Gender differences will affect how to use the toilet. This aims to give the players an understanding of differences in gender and use of toilets. In addition, the player is allowed to select the type of water closet like the squat or sitting toilet. Thus, the players may adjust to the water closet in their environment.

c) Scenario 1.1. Shower menu provides the player with the steps of taking a bath. It starts with knowing the bathroom and bathtub, getting undressed, applying soap to the body, and getting dressed. In this menu, the player is introduced to bathroom and things that can be used when taking a shower. The player is also given knowledge about the steps when taking a bath.

d) Scenario 1.2. Defecating menu teaches the players how to use the toilet for bowel movements. The game begins with an introduction to the toilet in accordance with their choices like squat or sitting toilet. If they choose a squat toilet, the game will teach them how to use a squat toilet. They are taught the steps of defecating. It starts with knowing the urge of defecating and bathroom, taking off the pants, using the toilet, flushing, washing hands, and putting on the pants.

e) Scenario 1.3. Urinating menu teaches the players how to use the toilet to urinate. Similar to Bowel Movement menu, urinating also comes with many steps.

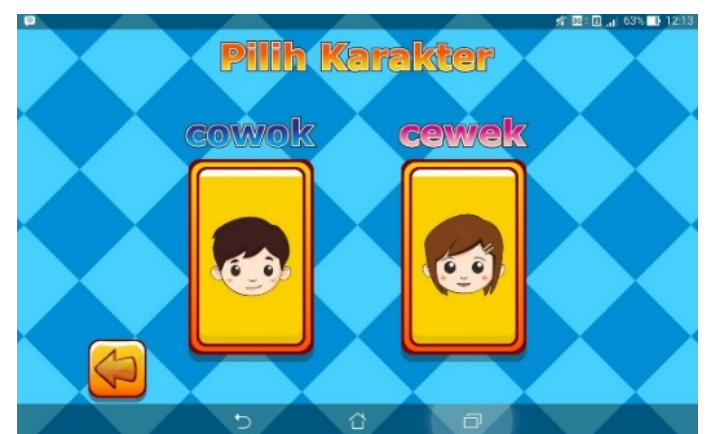

Fig. 3. The page to select a character. The labels read: Choose a character 'Pilih Karakter', male 'Cowok', female 'Cewek'.

f) Scenario 1.4. Washing Hands menu teaches the player how to wash hands. This aims to create awareness for the players in maintaining the hygiene of their hands, especially after using the toilet.

g) Scenario 1.5. For Holding in Urine and Feces menu, the players are taught to hold in urine and feces, so that they neither defecates nor urinates in improper places.

h) Scenario 2.0. Help menu contains instructions on how to play the toilet game.

i) Scenario 3.0. About menu displays the information about the toilet game.

\section{Development}

The game is developed using Unity Game Engine software. Unity software is selected to make the developed game be played in various platforms such as Windows, Mac, Linux, Android, and iOS. The followings are several displays of the proposed game. In Fig. 3, there are choices of characters that can be selected by the players, boy or girl.

The selection of these characters aims to give a clear material in accordance with the needs of children [18]. This selection will affect the toilet training materials contained in the game. In addition to selecting a character, this game provides options regarding the water closet that can be adjusted with the background of the players. The page to select the water closet is shown in Fig. 4.

Because of the diverse background of the children with autism, this facility is provided to help them to have the ability to make use of toilets that they find in their surrounding. The option to change the character or theme should be available in the beginning part of the game, so it does not interfere with the game and can be set easily [34]. The player is also given material about various objects that are found in the bathroom. This aims to introduce children to the functions of 
Cite this article as: R. Kurniawan, W. M. Purnamasari, R. Rakhmawati, and D. P. E. Jalaputra, "Development of Game for Self-Help Toilet Learning for Children with Autism”, CommIT (Communication \& Information Technology) Journal 12(1), 1-12, 2018.

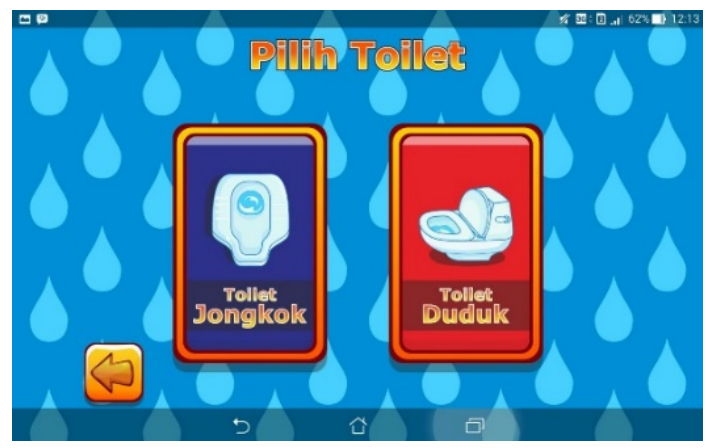

Fig. 4. The page to select a water closet. The labels read: Choose a toilet 'Pilih Toilet', squat-type toilet 'Toilet Jongkok', sitting-down toilet 'Toilet Duduk'.

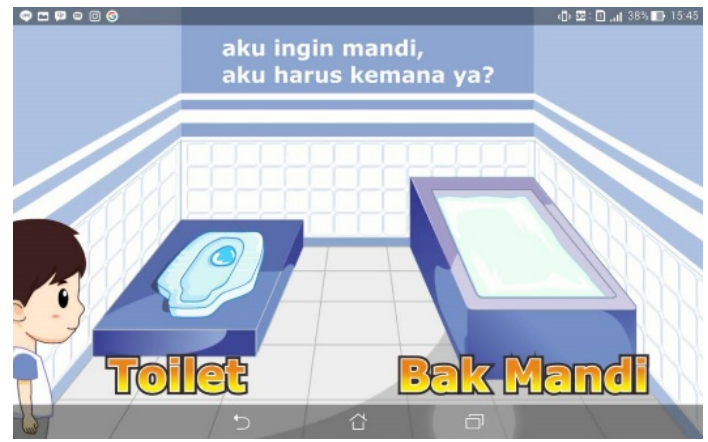

Fig. 5. The page about bathroom introduction. The labels read: Toilet 'Toilet', bathtub 'Bak Mandi'.

the objects in the bathroom. The introduction of the bathroom is shown in Fig. 5 .

In addition to using the bathroom, the players are also taught how to hold in feces. This is one of the important materials. Children with autism should be given the understanding about not to defecate in improper places. The display of holding in feces is in Fig. 6.

This game also contains a mini-game during the scene of defecating. The mini-game in Fig. 7 is when the players can break the bubbles until they finish defecating.

Figure 8 shows the main display of the game. In the main page, the default display provides options such as showers, sinks, water closet, or holding in feces randomly. There is a menu that displays several options so that teachers can customize the materials. Meanwhile, Fig. 9 shows game feedback in the form of compliments to the player.

\section{RESULTS AND DiscusSION}

The assessment of the system functionality is done by assessing the display and functionality of the game on certain devices. The list of devices used for this

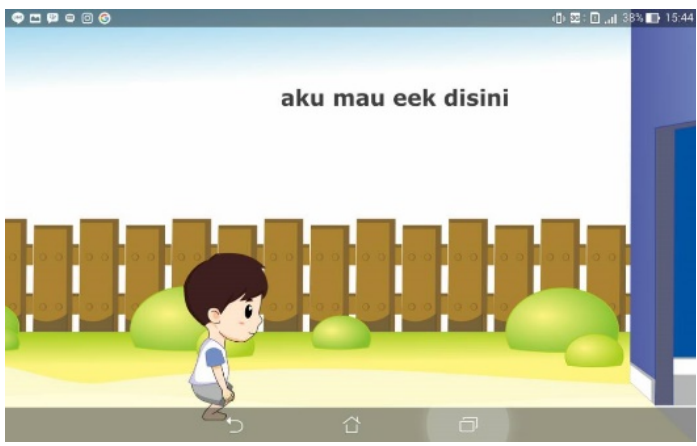

Fig. 6. The page of holding-in feces. The label reads: I wanna defecate in here 'aku mau eek di sini'.

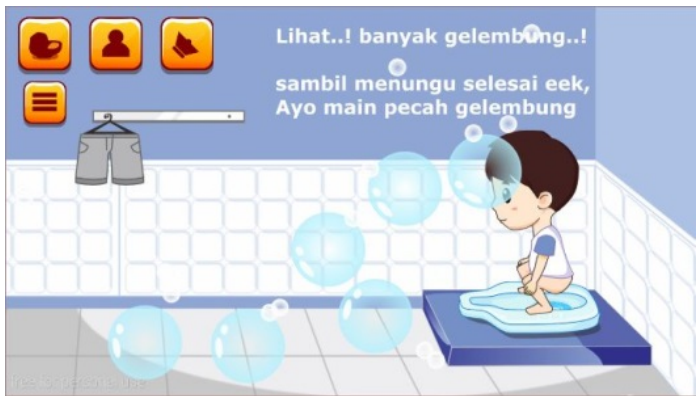

Fig. 7. The page of mini-game. The labels read: Look..! Many Bubbles..! 'Lihat..! Banyak gelembung..!', while defecating, let play bubble 'sambil menunggu selesai eek, Ayo main pecah gelembung'.

assessment is presented in Table I. Based on the results of the system functionality assessment, the game display shows the expected display. The objects in the game look proportional on all devices. The existing functions in the game can run well on all the devices.

\section{A. Implementation}

The implementation phase aims to test the developed game. This test is to find out about the quality of the materials found in the game and the childrens responses to the game. The game is tested in Dian Amanah SLB with six children with autism with a different spectrum.

1) Material assessment: Material assessment to teachers and specialists is done to determine the quality of the game materials. The test is done by the following experts: two teachers who teach children with autism, children psychologist, and specialist. They have already worked with children with autism for more than seven years. Interview of material assessment is shown in Fig. 10. According to teachers and specialists, the objects found in the game are simple. The simple and few objects can make children focus on playing. It is easier for the children to understand the purpose of the 
Cite this article as: R. Kurniawan, W. M. Purnamasari, R. Rakhmawati, and D. P. E. Jalaputra, "Development of Game for Self-Help Toilet Learning for Children with Autism", CommIT (Communication \& Information Technology) Journal 12(1), 1-12, 2018.

TABLE I

List OF DEVICES USED FOR ASSESSMENT.

\begin{tabular}{lllcc}
\hline Name of Device & Android Version & CPU (GHz) & RAM (GB) & Screen Resolution (Pixel) \\
\hline Asus Fonepad 8 FE380CG & 4.4 KitKat & Quadcore 1.33 & 2 & $1280 \times 800$ \\
Samsung Galaxy Tab 2 10.1 & 4.1 Jelly Bean & Dualcore 1.0 & 1 & $1280 \times 800$ \\
Samsung Galaxy Note Pro 12.2 & 4.4 KitKat & Quadcore 2.3 & 3 & $2560 \times 1600$ \\
\hline
\end{tabular}

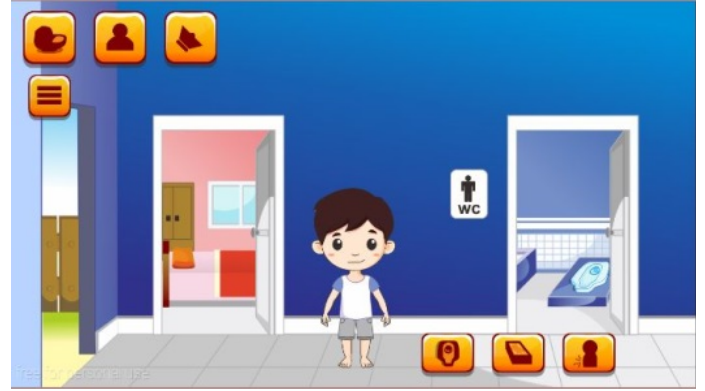

Fig. 8. The display of the main page of the game.

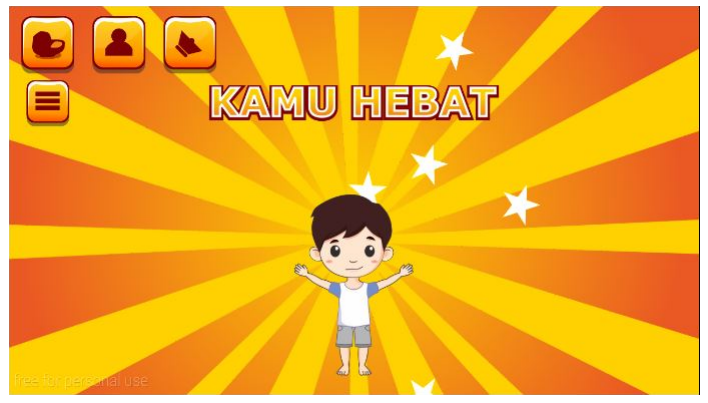

Fig. 9. The display of the game feedback. The label reads: You are great 'Kamu Hebat'.

game, so they will be likely to understand more about toilet training. However, there are still some unclear instructions. In giving instructions for children with autism, it should be short and clear.

2) Implementation assessment: Implementation assessment is conducted to six children with autism using observation communication analysis method. These six children have the characteristics described in Table II. The respondents are selected based on the criteria of self-help regarding urination, bowel movement, and personal hygiene. All the respondents in this study are still in need of assistance in toileting skills from teachers at the studied location.

During the assessment process, observation and recording of the children's behavior when playing the game with their teacher are shown in Fig. 11.

Then, the data are quantified together with psychologists to measure some indicators in Fig. 12. These indicators are recorded to determine the children's response to the game. The indicators consist of:

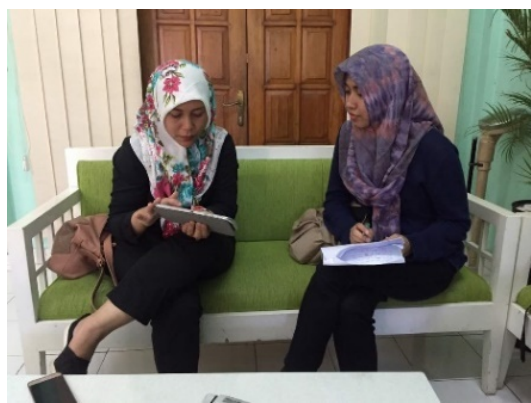

Fig. 10. The interview with the specialist.

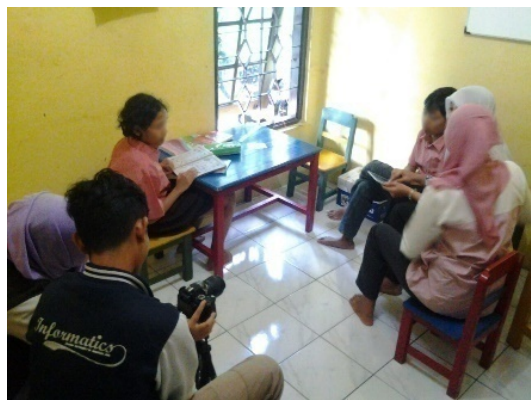

Fig. 11. The process of recording and observation.

1) Verbal interest. Verbal interest is observed by seeing how often children spoke positively about the game.

2) Non-verbal interest. Non-verbal interest is observed from the movements of the respondents while playing the game. These movements can be in the form of shaking their legs, smiling, or laughing.

3) Verbal disinterest. Verbal disinterest is measured by observing whether the respondents speak negative things about the game or refuse to play.

4) Non-verbal disinterest. Non-verbal disinterest is seen from the respondents' behavior when playing. Some movements showing disinterest are putting the gadget down, not focusing on playing, and not wanting to play.

5) Interaction with teachers. Interaction with the teacher is seen from the respondents response to questions asked by the teachers, questioning the teachers, and looking towards the teachers. 
Cite this article as: R. Kurniawan, W. M. Purnamasari, R. Rakhmawati, and D. P. E. Jalaputra, "Development of Game for Self-Help Toilet Learning for Children with Autism”, CommIT (Communication \& Information Technology) Journal 12(1), 1-12, 2018.

TABLE II

THE RESPONDENT'S CHARACTERISTICS.

\begin{tabular}{cclcccc}
\hline No & Respondent & Verbal / Non-Verbal & Age & $\begin{array}{l}\text { Understanding } \\
\text { sic command }\end{array}$ & ba- & Toileting skills \\
\hline 1 & A & Verbal & 11 & Yes & Lacking & Yes \\
2 & B & Verbal & 7 & Yes & Very lacking & No \\
3 & C & Verbal & 8 & Yes & Very lacking & Yes \\
4 & D & Non-Verbal & 12 & Yes & Lacking & No \\
5 & E & Non-Verbal & 9 & Yes & Lacking & Yes \\
6 & F & Verbal & 10 & Yes & Lacking & Yes \\
\hline
\end{tabular}

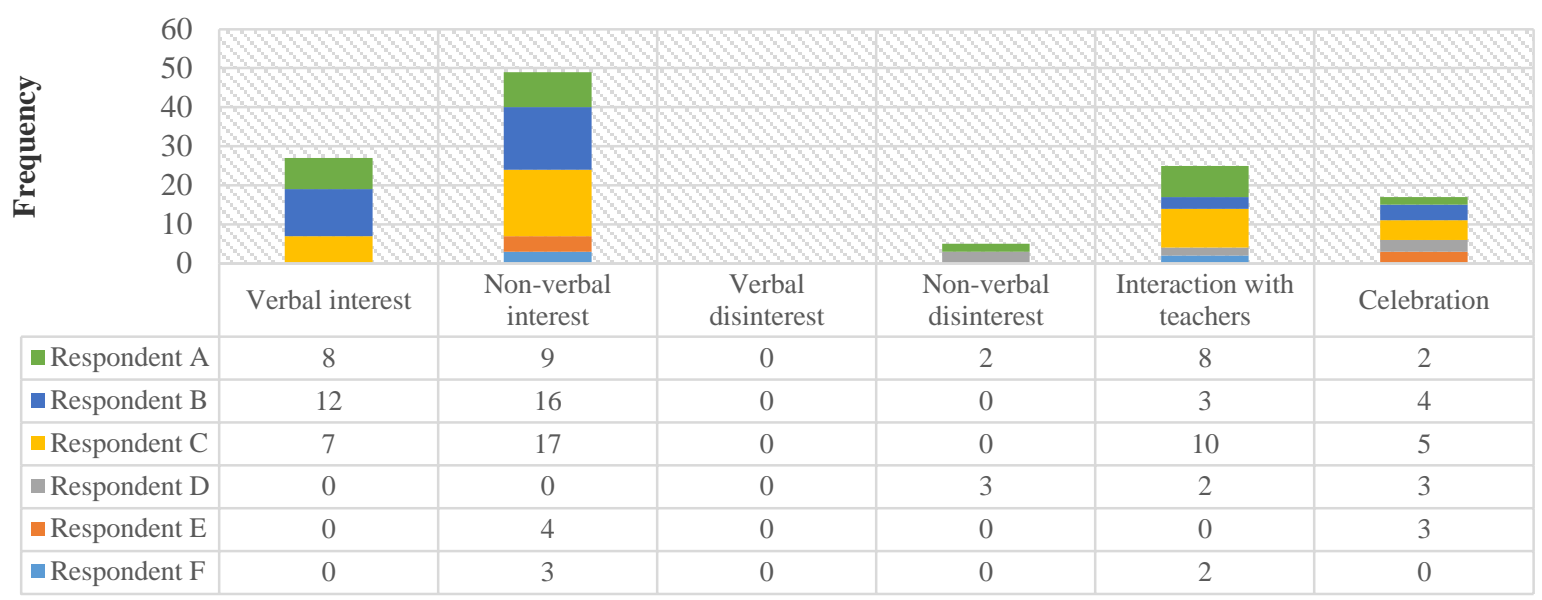

Fig. 12. The results of the communication analysis.

6) Celebration. The celebration is how the respondents respond when they complete the game. This can be fun expressions like "hurray", "yes", or smiling and making "high five" with the teacher. One of the main problems of children with autism is difficulty attracted to new things. Children tend not to play games because they prefer to browse or watch favorite channels on YouTube if they are given a smartphone. To find out if the child is interested in this game or not, it can be seen by measuring the number of Verbal interest and Non-verbal interest then compared with the number of Verbal disinterest and Non-verbal disinterest. Interaction with teachers is measured to understand whether the game eliminates the child's interaction with the teacher. So, it can be seen that this game does not make children more indifferent to the people around him. The celebration is measured to understand the child's emotional integration with the game. The result of observation communication analysis can be seen in Figure 12. This figure depicts that children with autism tend to be interested in playing the proposed games.

3) Testing of Learning Outcomes: For a week, teachers teach toileting skills to all the respondents us- ing the proposed game. Figure 13 shows the process of an interview with teachers. In general, according to the interview result with the teachers, all the respondents have an increased understanding related to personal hygiene. They have had an awareness of washing hands when their hands are dirty. In addition, all the respondents can identify the location of the toilet and go to the toilet if they have the urge to urinate. However, some of the respondents cannot clean themselves and feces after a bowel movement. In addition, respondent $\mathrm{C}$ still cannot put on his pants after a bowel movement.

\section{B. Evaluation}

The final phase is an evaluation. Evaluation of the game that had been developed was based on the results of testing. Based on the results of observation communication analysis, the game has been accepted by children with autism. This is evident from the fact that there are more respondents who show both verbal and non-verbal interests. When playing, children are enthusiastic. In addition, the average time in which the respondents are willing to play this game in one testing session is 11 minutes. This also indicates that the developed game has been in accordance with the targeted teaching and learning needs or at least 10 minutes. As an evaluation of the use of the game, 
Cite this article as: R. Kurniawan, W. M. Purnamasari, R. Rakhmawati, and D. P. E. Jalaputra, "Development of Game for Self-Help Toilet Learning for Children with Autism", CommIT (Communication \& Information Technology) Journal 12(1), 1-12, 2018.

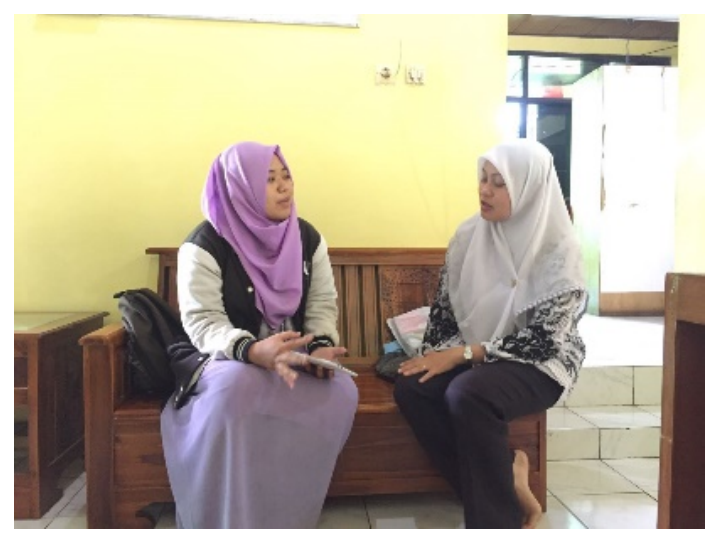

Fig. 13. The interview regarding the material for testing with a teacher.

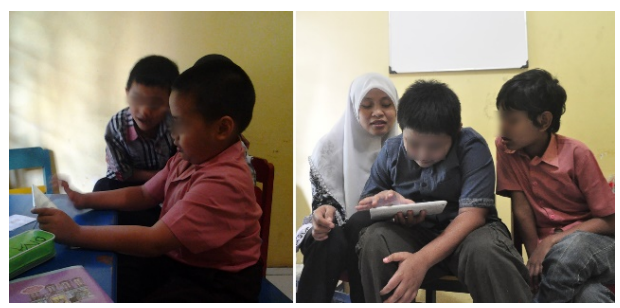

Fig. 14. Children play the game together.

Fig. 14 shows several children gather to see one of them play the game and Fig. 15 shows a child who is smiling while playing.

Figures 14 and 15 show that the game is interesting for children with autism. When playing the game, the interaction between a child and teacher is evident in Fig. 16.

This illustrates that this game can be a good learning media, and it has met the targeted teaching and learning needs that children do not lose interactions with their teacher during gaming. Children can also accept to obey the instruction given. For example, there is no one that demonstrates rejection when they ask to stop playing. It is evidence that this game do not cause addiction.

\section{CONCLusion}

This study has resulted a new learning medium for training toileting skills for children with autism. It is in the form of a video game. The developed game has applied design and materials related to toileting in accordance with the needs of children. Based on the overall assessment, the respondents show positive results to this game. Graphs of verbal and non-verbal interests show that almost all of the respondents are interested in the game. Celebration graph also shows that the respondents can enjoy the game. The game

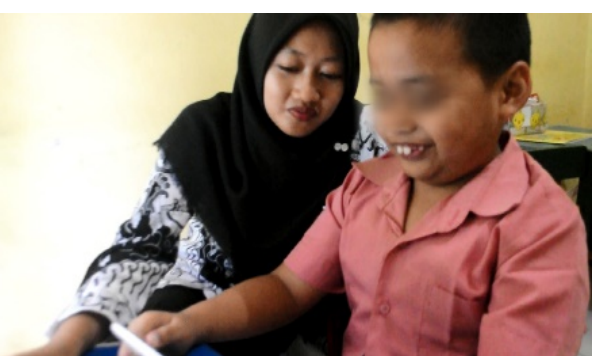

Fig. 15. A child is smiling when playing the game.

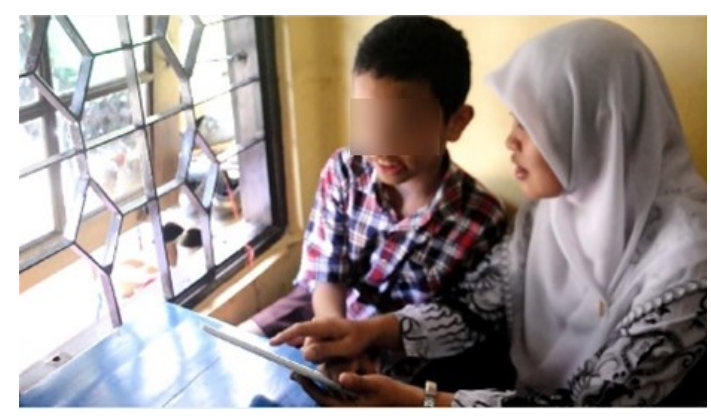

Fig. 16. Interaction of a child with a teacher

is also proved to be a good learning medium. It can maintain the interaction between children with a teacher. In other words, this game does not make the child get addicted to the gadget, something that most people are concerned with. The overall materials in the game meet the criteria as good learning medium for children with autism. The fact that this game does not have too many objects can make children focus on receiving the materials. From the assessment results of learning, children with autism, in general, have an increased toileting skill even though some of them still show learning delays. As a follow-up study, the researchers plan to conduct an advanced study that involves a wider range of target groups (children with autism) with a longer intervention time to test the level of success of the proposed game.

\section{REFERENCES}

[1] D. Keen, K. L. Brannigan, and M. Cuskelly, "Toilet training for children with autism: The effects of video modeling," Journal of Developmental and Physical Disabilities, vol. 19, no. 4, pp. 291303, 2007.

[2] K. Kroeger and R. Sorensen-Burnworth, "Toilet training individuals with autism and other developmental disabilities: A critical review," Research in Autism Spectrum Disorders, vol. 3, no. 3, pp. 607-618, 2009. 
Cite this article as: R. Kurniawan, W. M. Purnamasari, R. Rakhmawati, and D. P. E. Jalaputra, "Development of Game for Self-Help Toilet Learning for Children with Autism", CommIT (Communication \& Information Technology) Journal 12(1), 1-12, 2018.

[3] T. R. Schum, T. M. Kolb, T. L. McAuliffe, M. D. Simms, R. L. Underhill, and M. Lewis, "Sequential acquisition of toilet-training skills: a descriptive study of gender and age differences in normal children," Pediatrics, vol. 109, no. 3, pp. e48-e48, 2002.

[4] N. J. Blum, B. Taubman, and N. Nemeth, "Relationship between age at initiation of toilet training and duration of training: A prospective study," Pediatrics, vol. 111, no. 4, pp. 810-814, 2003.

[5] L. Flynn and O. Healy, "A review of treatments for deficits in social skills and self-help skills in autism spectrum disorder," Research in Autism Spectrum Disorders, vol. 6, no. 1, pp. 431-441, 2012.

[6] K. Francis, A. Mannion, and G. Leader, "The assessment and treatment of toileting difficulties in individuals with autism spectrum disorder and other developmental disabilities," Review Journal of Autism and Developmental Disorders, vol. 4, no. 3, pp. 190-204, 2017.

[7] L. Tsai, M. A. Stewart, and G. August, "Implication of sex differences in the familial transmission of infantile autism," Journal of Autism and Developmental Disorders, vol. 11, no. 2, pp. 165-173, 1981.

[8] F. R. Cicero and A. Pfadt, "Investigation of a reinforcement-based toilet training procedure for children with autism," Research in Developmental Disabilities, vol. 23, no. 5, pp. 319-331, 2002.

[9] D. Sells-Love, L. M. Rinaldi, and T. McLaughlin, "Toilet training an adolescent with severe mental retardation in the classroom: A case study," Journal of Developmental and Physical Disabilities, vol. 14, no. 2, pp. 111-118, 2002.

[10] B. L. Baker, A. J. Brightman, J. B. Blacher, L. J. Heifetz, S. R. Hinshaw, and D. M. Murphy, Steps to independence: Teaching everyday skills to children with special needs. ERIC, 2004.

[11] N. J. Dalrymple and L. A. Ruble, "Toilet training and behaviors of people with autism: Parent views," Journal of Autism and Developmental Disorders, vol. 22, no. 2, pp. 265-275, 1992.

[12] V. Kleeberger and P. Mirenda, "Teaching generalized imitation skills to a preschooler with autism using video modeling," Journal of Positive Behavior Interventions, vol. 12, no. 2, pp. 116127, 2010.

[13] F. Besler and O. Kurt, "Effectiveness of video modeling provided by mothers in teaching play skills to children with autism." Educational Sciences: Theory and Practice, vol. 16, no. 1, pp. 209-230, 2016.
[14] M. Sherer, K. L. Pierce, S. Paredes, K. L. Kisacky, B. Ingersoll, and L. Schreibman, "Enhancing conversation skills in children with autism via video technology: Which is better, self or other as a model?" Behavior Modification, vol. 25, no. 1, pp. 140-158, 2001.

[15] A. R. Post and M. A. Kirkpatrick, "Toilet training for a young boy with pervasive developmental disorder," Behavioral Interventions, vol. 19, no. 1, pp. 45-50, 2004.

[16] N. Azrin and R. Foxx, "A rapid method of toilet training the institutionalized retarded," Journal of applied behavior analysis, vol. 4, no. 2, pp. 8999, 1971.

[17] R. Foxx and N. Azrin, "A rapid method of toilet training children." in Proceedings of the Annual Convention of the American Psychological Association. American Psychological Association, 1973.

[18] B. Drysdale, C. Y. Q. Lee, A. Anderson, and D. W. Moore, "Using video modeling incorporating animation to teach toileting to two children with autism spectrum disorder," Journal of Developmental and Physical Disabilities, vol. 27, no. 2, pp. 149-165, 2015.

[19] N. Bainbridge and B. Smith Myles, "The use of priming to introduce toilet training to a child with autism," Focus on Autism and Other Developmental Disabilities, vol. 14, no. 2, pp. 106-109, 1999.

[20] C. Y. Q. Lee, A. Anderson, and D. W. Moore, "Using video modeling to toilet train a child with autism," Journal of Developmental and Physical Disabilities, vol. 26, no. 2, pp. 123-134, 2014.

[21] D. Richardson, "Toilet training for children with autism," Nursing Children and Young People, vol. 28, no. 2, p. 16, 2016.

[22] J. Jeuring, R. van Rooij, and N. Pronost, "The 5/10 method: A method for designing educational games," in International Conference on Games and Learning Alliance. Springer, 2013, pp. 364369.

[23] D. Thompson, T. Baranowski, R. Buday, J. Baranowski, V. Thompson, R. Jago, and M. J. Griffith, "Serious video games for health: How behavioral science guided the development of a serious video game," Simulation \& gaming, vol. 41, no. 4, pp. 587-606, 2010.

[24] A. Bandura, "Social cognitive theory: An agentic albert bandura," Asian Journal of Social Psychology, vol. 2, no. 1, pp. 21-41, 1999.

[25] R. M. Ryan and E. L. Deci, "Self-determination theory and the facilitation of intrinsic motivation, social development, and well-being." American 
Cite this article as: R. Kurniawan, W. M. Purnamasari, R. Rakhmawati, and D. P. E. Jalaputra, "Development of Game for Self-Help Toilet Learning for Children with Autism", CommIT (Communication \& Information Technology) Journal 12(1), 1-12, 2018.

psychologist, vol. 55, no. 1, p. 68, 2000 .

[26] R. E. Petty, J. T. Cacioppo, and D. Schumann, "Central and peripheral routes to advertising effectiveness: The moderating role of involvement," Journal of Consumer Research, vol. 10, no. 2, pp. 135-146, 1983.

[27] S. Stefany, "The effect of motivation on purchasing intention of online games and virtual items provided by online game provider," CommIT (Communication and Information Technology) Journal, vol. 8, no. 1, pp. 22-27, 2014.

[28] M. C. Green, J. J. Strange, and T. C. Brock, Narrative impact: Social and cognitive foundations. Taylor \& Francis, 2003.

[29] M. Tincani, "Comparing the picture exchange communication system and sign language training for children with autism," Focus on autism and other developmental disabilities, vol. 19, no. 3, pp. 152-163, 2004.

[30] B. Abirached, Y. Zhang, and J. H. Park, "Understanding user needs for serious games for teaching children with autism spectrum disorders emotions," in EdMedia: World Conference on Educational Media and Technology. Association for the Advancement of Computing in Education (AACE), 2012, pp. 1054-1063.

[31] R. R. Morris, C. R. Kirschbaum, and R. W. Picard, "Broadening accessibility through special interests: A new approach for software customization," in Proceedings of the 12th international ACM SIGACCESS conference on Computers and accessibility. ACM, 2010, pp. 171-178.

[32] J. Hailpern, K. Karahalios, and J. Halle, "Creating a spoken impact: Encouraging vocalization through audio visual feedback in children with asd," in Proceedings of the SIGCHI Conference on Human Factors in Computing Systems. ACM, 2009, pp. 453-462.

[33] S. E. Smaldino, D. L. Lowther, J. D. Russell, and C. Mims, Instructional technology and media for learning. Pearson Merrill Prentice Hall Upper Saddle River, NJ, 2008.

[34] N. Mahmood, "Designing video games and interactive applications to enhance learning in children with autism spectrum disorders," Ph.D. dissertation, Texas A \& M University, 2012.

[35] R. Kurniawan, A. Mahtarami, and R. Rakhmawati, "Gempa: Game edukasi sebagai media sosialisasi mitigasi bencana gempa bumi bagi anak autis," Jurnal Nasional Teknik Elektro dan Teknologi Informasi (JNTETI), vol. 6, no. 2, 2017.

[36] R. Kurniawan, I. Muhimmah, and A. Ramadhan,
"Game pembelajaran ekspresi dan emosi wajah untuk anak autis," Teknomatika, vol. 9, no. 1, pp. 1-12, 2016.

[37] R. M. Rias and S. R. Dehkordi, "Computer game approach for children with autism spectrum disorder: A pilot study," in 6th WSEAS World Congress: Applied Computing Conference, 2013, pp. $174-179$.

[38] A. Wilkins, R. Cleave, N. Grayson, and L. Wilson, "Typography for children may be inappropriately designed," Journal of Research in Reading, vol. 32, no. 4, pp. 402-412, 2009.

[39] J. M. Keller, "Development and use of the arcs model of instructional design," Journal of Instructional Development, vol. 10, no. 3, pp. 2-10, 1987. 